Editor's Introduction: Mitchell S. Cappell suggests that mentors should be listed as co-first authors in research publications. Many librarians work in or are affiliated with workers in the health sciences research field. We have an interest in how researchers wish to be presented in publication. This letter also provides some insight to the thinking of some academicians.

\title{
Equal authorship for equal authors: personal experience as an equal author in twenty peer-reviewed medical publications during the last three years
}

\author{
Mitchell S. Cappell, MD, PhD \\ See end of article for author's affiliation.
}

DOI: http://dx.doi.org/10.3163/1536-5050.104.4.022

\begin{abstract}
Keywords: Authors, Authorship, Equal Authors, Medical Indexes, PubMed, MEDLINE, National
\end{abstract} Library of Science, Bibliography, Medical References, Curriculum Vitae

To the editor, Authors' contributions to medical publications are semi-quantitatively assessed by order of authorship, with earlier listed authors generally having increasingly important contributions. Standard medical indexes, such as PubMed or MEDLINE, uniformly list authors of publications in peer-reviewed journals sequentially, without provision for designating equal authorship for equal contributors. This omission can discriminate against the second of equal authors, who is viewed as a lesser contributing author. This letter analyzes this problem and proposes an equitable solution, based on personal experience with twenty publications during the last three years. This work received an exemption/approval by the William Beaumont Hospital Institutional Review Board on January 11, 2016.

The two end points of authorship, first and last authors, are traditionally reserved for the primary (first) author and senior author (mentor), respectively. In articles in basic science, the first author is the primary investigator, whereas the last author is typically the senior investigator who supervises the project, administers the laboratory in which the experiments are conducted, and has been awarded the research grant funding the project. Similarly, in clinical articles, the first author is the investigator who performs the primary research, whereas the last author is the mentor who supervises the research.
Sequential designation of author contributions can, however, misattribute those contributions, especially vis-à-vis first and last authors. As a senior clinical academic gastroenterologist, with more than 30 years of service in academic gastroenterology and 253 publications in peer-reviewed journals, as listed in PubMed [1], I keenly appreciate this problem. I nearly always serve as mentor in clinical research projects. As mentor, I defer first authorship to the mentee and accept the position of last (senior) author. I concede first authorship because the mentee typically has few or nil preexisting publications and may depend upon first authorship in an anticipated, forthcoming publication to promote career advancement, say, from gastroenterology fellow to assistant professor.

This arrangement, however, denigrates mentors' contributions. The mentee generally collects the primary data, performs the initial literature review, and writes the first draft of the manuscript. Even though the mentor may spend less time on the project than the mentee, the mentor usually contributes the most to manuscript quality due to greater training and experience. For example, as mentor, I generally conceive the research topic, plan the investigation, outline the manuscript, edit the manuscript continuously until submission, and modify the manuscript in response to reviewers' criticisms. Furthermore, as senior author, I am the invitee for an invited review. 
Equal authorship equitably balances the greater time spent by a mentee versus the greater impact of a mentor on manuscript quality. It provides manifold benefits, including cementing equal status for mentee and mentor to promote mentorship, avoiding rivalry for first authorship, equitably attributing author contributions, and retaining the mentee's advantage in career advancement because the mentee is still listed as first author. Since late 2013, I and my coauthors have listed the mentee and mentor as equal authors in twenty publications listed in PubMed, including ten full-length articles and ten case reports (excluding letters to the editor) (four publications referenced as [2-5], another sixteen publications listed by PMID\# [6]).

In my experience, all the journals initially opposed the designation of equal authorship. Indeed, one distinguished gastroenterology journal states in its guidelines, "Designation of co-first authors is not permitted" [7]. Journal opposition to this designation was manifested by not including equal authorship in the initial publication proofs or in the first corrected proofs, despite the authors' request, and only printing equal authorship in the second corrected proofs and final publication after the authors insisted that this designation be included.

The National Library of Medicine uniformly ignores equal authorship designations. For example, all twenty of my above publications are listed in PubMed without the designation of equal authors or equal authorship [1]. I ask this prestigious, superb bibliographic index to consider following the designation of authorship established by the journals themselves and designate equal authorship for equally contributing authors. The role of the National Library of Medicine is to record and not arbitrate authorship. The specific mechanism to designate equal authorship in PubMed is left up to the National Library of Medicine. A universally accepted symbol could be created to designate equal authors. Equal authorship should promote fairness in authorship and facilitate mentorship, both desirable goals in academic medicine.

\section{CONFLICT OF INTEREST}

The author has no conflict of interest in this letter. This paper does not discuss any confidential pharmaceutical industry data reviewed by Mitchell S. Cappell as a consultant for the US Food and Drug Administration Advisory Committee on
Gastrointestinal Drugs. Cappell is a member of the speaker's bureau for AstraZeneca. This paper does not discuss any drug manufactured or marketed by AstraZeneca.

\section{REFERENCES}

1. National Library of Medicine. PubMed: search results Cappell MS [Internet]. The Library [cited 8 Jan 2016].

$<$ http://www.ncbi.nlm.nih.gov/pubmed/? term=Cappell+MS $>$. (As of January 15, 2016, 253 articles by "Cappell MS" listed in PubMed)

2. Nojkov B, Cappell MS (Nojkov and Cappell are equal authors). Gastrointestinal bleeding from Dieulafoy's lesion: clinical presentation, endoscopic findings, and therapy. World J Gastrointest Endosc. 2015;7(4):295-307. PMID: 25901208. (Published online 16 Apr 2015.) 3. Sharma N, Cappell MS (Sharma and Cappell are equal authors). Gastrointestinal and hepatic manifestations of Ebola virus infection. Dig Dis Sci. 2015 Sep;60(9):2590603. DOI: http://dx.doi.org/10.1007/s10620-015-3691-z. Epub 2015 May 14. (PMID: 25972150).

4. Copelan A, Chehab M, Dixit P, Cappell MS (Copelan and Cappell are equal authors). Safety and efficacy of angiographic occlusion of duodenal varices as an alternative to TIPS: review of 32 cases. Ann Hepatol. 2015;14(3):369-79 (PMID: 25864218).

5. Nojkov B, Cappell MS (Nojkov and Cappell are equal authors). Distinctive aspects of peptic ulcer disease, Dieulafoy's lesion, and Mallory-Weiss syndrome in patients with advanced alcoholic liver disease or cirrhosis. World J Gastroenterol. 2016 Jan 7;22(1):446-66. DOI: http://dx.doi.org/10.3748/wjg.v22.i1.446.

6. The other 16 publications listing authors as equal authors are identified by their PMID numbers, as follows: 24370782, 24555981, 24605013, 24891928, 25954476, 26657924, 23400736, 23907335, 24094872, 24365040, 25138902, 25224171, 25332272, 25771066, 26366309, 26640349.

7. Guidelines and requirements for manuscript revision: systematic reviews. World J Gastroenterol. Pleasanton, CA: Baishideng Publishing Group. p. 5. Latest version [updated 29 Jun 2015].

\section{AUTHOR'S AFFILIATION}

Mitchell S. Cappell, MD, PhD, Chief, Division of Gastroenterology \& Hepatology, William Beaumont Hospital, Royal Oak, MI 48073; and Professor of Medicine, Oakland University William Beaumont School of Medicine, Royal Oak, MI 48073 